\title{
Stochastic Multicriteria Acceptability Analysis of EV Sharing in Nordic Rural Areas Affected by Seasonal Residence and Counterurbanization
}

\author{
Johannes Einolander \\ Aalto University, School of Engineering, \\ Department of Mechanical Engineering \\ Espoo, Finland \\ johannes.einolander@aalto.fi
}

\author{
Annamari Kiviaho \\ Aalto University, School of Engineering, \\ Department of Built Environment \\ Espoo, Finland \\ annamari.kiviaho@aalto.fi
}

\begin{abstract}
Sharing economy and shared mobility has become a widespread trend in urban areas worldwide. Due to lower population density, car sharing, and other shared mobility applications are generally not accessible in rural areas. This paper utilizes a Stochastic Multicriteria Acceptability Analysis (SMAA) method to assess the criteria importance in siting problem of rural electric vehicle (EV) sharing systems. Nordic rural areas are used as a case study in this analysis, and we compare their feasibility to act as a pilot location for $E V$ sharing. Seasonal residence, rural tourism and counterurbanization are common themes in Nordic rural areas and act as enablers for rural vehicle sharing. Based on our novel application of SMAA to this context, we found that Swedish rural areas would be most suitable for a rural EV sharing pilot. High tourism and low vehicle ownership were identified to be the most important criteria for this siting problem.
\end{abstract}

\section{Introduction}

The transition from ownership to sharing economy has been a global trend during the recent years [1-3]. The concept of sharing economy is however still ambiguous, and as Schor [3] points out it is almost impossible to come up with a solid definition and boundaries for the term. For instance, traditional bed and breakfasts are not considered to be part of the sharing economy, whereas Airbnb is often regarded as one of the most popular sharing economy platforms [3]. Generally, sharing economy can be thought as an umbrella term for a wide range of services, businesses and activities that are somehow connected to sharing something [4].

Shared mobility is one example of sharing economy applications [5]. Shared mobility can further be divided into "ride sharing" and "asset sharing" applications, of which car sharing is one example [6]. Car sharing has recently become a viable alternative to car ownership as the users gain benefits of a private vehicles, but don't have to worry about the costs and responsibilities of car ownership [7,8]. Car sharing is also an opportunity for sustainable transportation development, and car sharing has, for instance, been shown to reduce $\mathrm{CO} 2$ emissions $[9,10]$.

In 2010s, in conjunction with the electrification of transport megatrend, electric vehicles (EVs) have become common in car sharing operations [11]. EVs have multiple benefits over conventional internal combustion engine (ICE) vehicles, as they do not produce local emissions, can be powered by renewable energy and can provide ancillary services to support power grid stability $[10,12,13]$. EVs are however still more expensive than ICE vehicles, but in EV sharing applications the usage cost difference is minimal as the total cost of EV ownership is spread among multiple users $[11,14]$.

Vast majority of current car sharing operations are located in urban areas due to high population densities and easy accessibility $[7,10,15]$. Some researchers have however shown that even rural areas have potential, and be profitable locations, for car sharing operations $[11,15,16]$. Especially rural tourism increases the demand for shared vehicles in rural locations according to survey done in [11]. According to [11], many tourists are city dwellers who are open to new mobility services and might already have previous experience with car sharing services. Additionally, shared mobility solutions have been identified as an important part of the solution to tackle the mobility challenges present in rural areas [6]. Rural areas generally have limited public transportation networks, and the local population is highly dependent on private vehicles [6]. Rural shared mobility can also be seen as a way to support economic development of rural areas, and as a way to save substantial amounts of resources [6].

Car sharing companies operate mainly in urban areas due to easily predictable demand. However, as previous research has shown, there exists economic 
potential in rural areas for car sharing services. Research is however needed into which factors impact the potential of car sharing in rural areas, and which rural areas are potential locations for rural car sharing.

The aim of our study is to examine the influence of rural-specific criteria and preference weights in EVsharing siting problems. We utilize a with multicriteria decision analysis (MCDA) method called stochastic multicriteria acceptability analysis (SMAA) in a case study where we compare the suitability of Nordic rural areas for an EV sharing pilot. Utilization of the SMAAmethod gives important information on the significance and weights for decision-making criteria which were identified from previous literature.

Traditionally, multicriteria decision analysis is limited by uncertain and inaccurate information about decision-makers' preferences and criteria evaluations [17]. The SMAA method circumvents these uncertainties by utilizing the Monte Carlo method and different probability distributions in the analysis [1720]. SMAA was proposed in [18] for multicriteria decision problems where either the criteria measurements or preference weights are uncertain or missing [18-20].

The SMAA technique has been utilized in many different fields ranging from the healthcare sector to business and financial management [17]. It has also been utilized in various studies aiming to find the most suitable location for a specific operation. SMAA has, for instance, been used to determine optimal locations for waste treatment facilities, retail stores and air cargo hubs [21-23]

SMAA has not been previously applied in the context of sharing economy or EV-sharing. There however exists some previous studies where other MCDA approaches have been used in these contexts. For instance, [24,25] utilized analytical hierarchy process (AHP) in selection of optimal locations for urban car sharing stations. No previous scientific research exists where MCDA methods have been used with focus on rural car or EV-sharing. In this study the SMAA-method is used to assess optimal weights for EV-sharing pilot siting criteria in the context of Nordic rural areas.

\section{Background}

As stated previously, the vast majority of previous carsharing operations and research concentrate on densely populated urban areas $[10,11,15]$. Due to high population densities and lower percentage of car ownership, urban locations are the rational first choices for large profit oriented carsharing companies [16]. However, results of [11] show that rural residents are as open as urban residents towards carsharing. Contrary to urban population, the demand made by rural population is not enough to make rural carsharing systems economically viable [11]. That is, additional user groups and revenue streams are required in order to establish feasible carsharing operations to rural areas. Additional target groups for rural carsharing are, for instance, tourists and commuters [11]. Further, an EV-sharing operation can reach additional revenue from participating in demand response schemes during idle time periods.

Car sharing systems are generally divided into station-based one-way and two-way systems, to freefloating systems and to peer-to-peer systems [15]. In two-way car sharing systems, the vehicle pick-up and drop-off is conducted at the same car sharing station, whereas in one-way systems it is possible to drop-off the vehicle also to other stations [15]. The shared cars in free-floating systems have no dedicated stations, and vehicle pick-up and drop-off occur in dedicated zones [15]. Peer-to-peer car sharing systems differ from other systems, as there exists no dedicated operator and the shared vehicles belong to system participants [15]. From rural carsharing perspective, two-way systems enable shared mobility between rural and possible nearby urban areas with car sharing stations from the same vendor. One-way systems on the other hand are more dependent on local population and tourists arriving with public transportation. However, two-way systems are more expensive than one-way systems, and this should be taken into consideration in the planning stages of a venture [15].

The SMARTA project [6], set up by the EU to research sustainable shared mobility in European rural areas, sees shared mobility as an essential part of solution for the mobility issues in rural areas. Shared mobility and especially car sharing is seen as a way to complement public transport and decrease the dependence on private cars in rural environments [6]. The SMARTA consortium identifies rural tourism as one of the future priorities for shared rural mobility [6]. During the SMARTA and the MAMBA project, concentrating on the Baltic Sea Region, rural shared mobility solutions were piloted in 25 countries, with dedicated car sharing pilots in Germany, Belgium, UK and Sweden with promising results $[6,26]$.

According to survey made in [16], potential local users of rural carsharing are young, environmentally conscious and those that are better aware of carsharing services. The authors estimate that the potential for rural carsharing is $3.7 \%$ of local rural population holding a driver's license [16]. In urban areas, the potential of carsharing is larger and the user groups different than in rural context. Urban car sharers are typically middleaged and highly educated $[27,28]$. This user group also tends to be concerned about environmental issues and 
lives in densely populated urban areas [27]. The survey made in [29], shows that in particular EV sharing is attractive for younger non-car owner couples and younger families that use shared EVs to supplement their own cars. Based on the survey results, current users of carsharing services have overall an affinity towards EVs in contrary to conventional internal combustion vehicles in both carsharing and private vehicle ownership [29].

However, according to [30] individual demographics of carsharing users are not as important factors for carsharing success as the neighborhood characteristics. Most important neighborhood characteristics for carsharing success are low vehicle ownership, high household density and easy commuting by public transportation or walking [30,31]. In addition, high percentage of one person households, high percentage of population over the of age 24 and scarcity of parking space seems to support car sharing success in urban areas [30,31].

The research on which factors impact the potential of car sharing in rural areas, and which type of rural areas are potential locations for rural car sharing operations is however very scarce. As noted in [15], rural areas are excluded from almost all recent studies focusing on carsharing. Most approaches to carsharing viability are based heavily on modelling the expected demand through previously mentioned sociodemographic and neighborhood characteristics which is difficult and imprecise for rural scarcelypopulated areas mainly due to lack of data [15]. The results of the fleet operation simulation made in [15] prove that carsharing in rural areas can be profitable, especially if the low demand by rural residents can be compensated by demand from nearby urban areas. However, as the authors argue in [15], the characteristics of viable rural carsharing differ from urban instances, and more research is needed to fill existing research gaps. Our research aims to supplement existing knowledge by utilizing stochastic multicriteria acceptability analysis in siting of rural EV-sharing operations. The criteria used to assess possible locations for an EV-sharing pilot are based on previous literature, and the SMAA-method is used to assess optimal weights for these criteria in the context of Nordic rural areas.

\section{Case Nordic Rural Areas}

Multiple factors support Nordic rural areas as a viable pilot location for rural EV-sharing operations. Nordic countries are technologically oriented and early adaptors of shared services [32-34]. There exists several sharing economy operators in the Nordic countries, with the largest focus on vehicle and transportation segment
[33]. Nordic countries have strong climate policies and they are committed to ambitious climate goals [35]. Especially electric vehicles are identified to be essential tool to decarbonize transportation [35]. The Nordic countries additionally share similar geographical, climatic and historical background [36], climate policies [35], cultural heritage and ideological basis [37].

The Nordics are well-known for their nature and natural values which has led to widespread rural tourism [38-42]. In Nordic countries most of the main tourism attractions are located in rural areas $[39,43]$. The beauty of nature and unique geophysical features attracts international tourists to the rural areas of the region [39]. In addition to international tourism, domestic rural tourism is also very popular in the Nordic region [39]. For instance, berry picking, camping and other outdoor activities enabled by everyman's rights have been common recreational activities in Nordic countries for ages [44].

What deviates Nordic rural areas from most rural areas in the World is the widespread seasonal residence in these areas. It is very common in the Nordic countries to own a cottage or a "second home" located in a rural area [45-47]. It has been estimated that nearly half of the Nordic population have access to a second home, and the number of second homes in the Nordics has increased in the recent years [40]. Recent trend has been that people spend even more time in their second homes, and year-round usage is increasing $[47,48]$. On average, people spend multiple months in their second homes every year [48].

Second homeowners are typically urban dwellers who travel from their 'urban' permanent homes to 'rural' second homes or cottages for vacation and recreation. This flow of people from urban areas to rural second homes during weekends and holidays is sometimes referred to as "formidable seasonal counterurbanization" [49]. This causes significant seasonal population variability to rural areas [49], which in turn increases the number of potential users for shared services.

Seasonal residents are potential users of rural EVsharing due to multiple reasons. Urban second homeowners typically have at least some experience with shared services, which lowers the threshold of using these services in new locations. Car ownership is also less likely in urban population, which increases the need for car rentals or car sharing in rural areas $[30,50,51]$.

The Nordic countries also maintain extensive highquality statistical databases that are comparable with each other. These kind of comprehensive databases on rural population, seasonal residence, tourism and vehicle fleets by municipality are important and reliable 
criteria for multicriteria decision analysis. Information used in this study was mainly gathered from national statistics agencies of the Nordic countries and from the mutual Nordic Statistics database [52].

All the afore mentioned aspects make it reasonable to consider Nordic countries, and their rural areas, as prospective locations for viable EV-sharing ventures. Due to the similarities between the Nordic countries and their rural areas, it is also relatively effortless to expand demonstrated EV-sharing operations from the pilot country to other Nordic countries.

\section{Methodology}

\subsection{Stochastic Multicriteria Acceptability Analysis}

Stochastic multicriteria acceptability analysis (SMAA) is an advanced multicriteria decision analysis (MCDA) method family, able to deal with missing preference information and inaccurate or uncertain criteria values [17-19,53]. SMAA is an inverse method based on weight space analysis that computes support weights and stochastic acceptability indices for each alternative [18,19]. In SMAA, inaccurate or missing criteria and preference weights are represented as probability distributions [19]. The SMAA method is especially useful in situations with missing or uncertain preference information, and it can be used to describe criteria valuations, i.e., preferences, that are needed for each alternative to be the preferred one [19].

The SMAA-2 method used in this study, is an extension from the basic SMAA, developed especially for situations with imprecise criteria and weight information [19,20]. In addition to SMAA-2, we are utilizing the SMAA-O extension in this study for ordinal (ranked) criteria [20]. The ordinal criteria are treated as cardinal values by simulating rank consistent random cardinal values via ordinal-to-cardinal mapping [20].

Main results of the SMAA-2 analysis are rank acceptability indices, central weight vectors and confidence factors for each addressed alternative [53]. Rank acceptability index, $b_{i}^{r}$, represents the proportion of all weights where the alternative $i$ gains the rank $r$, and it is calculated with multidimensional integrals over criteria distributions and supporting rank weights with the following equation [19,20,54].

$$
b_{i}^{r}=\int_{X} f(\xi) \int_{W_{i}^{r}(\xi)} f(w) d w d \xi
$$

In equation $1, f(\xi)$ is the joint density function of criteria values treated as stochastic variables in space $X$, $W_{i}^{r}(\xi)$ is the set of favorable rank weights, and $f(w)$ is the weight density function. Extensive formulations can be found in [19]. The most favorable alternatives are those with high acceptabilities for best ranks, whereas alternatives with high acceptabilities for worst ranks should be avoided [19].

The central weight vector is the expected centroid, or center of gravity, of the favorable first rank weights of an alternative. This central weight vector can be calculated as a multidimensional integral over favorable first rank weights and criteria distributions with equation 2. [19,20,54]

$$
w_{i}^{c}=\int_{X} f(\xi) \int_{W_{i}^{1}(\xi)} f(w) d w d \xi / b_{i}^{1}
$$

This central weight vector with the assumed weight distribution can be estimated to represent the valuations, or preferences, of an average decision maker who supports the alternative $i$ [20]. That is, the alternative $i$ would be the preferred alternative with confidence $p_{i}^{c}$ if the decision maker would agree to preferences identical to the central weight vector. This confidence is the confidence factor of an alternative.

If the central weight factor is chosen, the confidence factor represents the probability that an alternative gains the first rank. Confidence factor is calculated by integrating over criteria distributions with equation 3. [19,20]

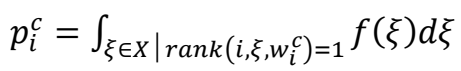

The multidimensional integrals in equations 1-3 are calculated with Monte Carlo simulation method where random numbers are generated for the criteria and weight vectors from their proprietary distributions $[19,20]$.

Overall, the SMAA results can aid in the decisionmaking process with missing preference information. The results are also useful in order to examine the impact different criteria preferences have on the decision-making problem. This study utilizes the open source SMAA implementation introduced in [54]. Detailed formulation and background for SMAA can be found from [18], for SMAA-2 from [19] and for the SMAA-O extension from [20].

\subsection{Criteria selection}

Multiple different criteria can be used to assess the potential of different locations for car sharing operations. In [25], the authors used potential users, potential travel demand, potential travel purposes and distance from existing stations as decision criteria for car sharing siting. In [24,55], a multicriteria decision approach was used based on following criteria: population density, parking difficulty and cost, mix of 
land use, presence of target groups, transit/multimodal access and vehicle ownership. Car sharing service locations in Istanbul were studied in [56] based on proximity factors, traffic congestion, car ownership, financial factors and availability of parking. A vast majority of this previous research focuses however, on urban locations, and studies focusing on localization of car sharing services to rural areas are virtually nonexistent [15].

Due to lack of previous research and differences between urban and rural areas, the criteria used in this rural EV-sharing localization multicriteria analysis have to emphasize different aspects than in cases concentrating on urban areas. The criteria used in this study are a combination of criteria used in urban car sharing localization studies and of criteria that take into consideration the special attributes and differences of Nordic rural areas. The five criteria that encompass the suitability of a Nordic rural area for EV-sharing operations are seasonal residency, tourism, experience with sharing services, car ownership and potential of ancillary services providable by EVs in the region. These criteria and their data sources are introduced in the following paragraphs.

The Community impact (CI) indicator, developed by Nordregio, is used in this study to describe the seasonal residency of Nordic rural areas. Nordregio, established by the Nordic Council of Ministers, is a leading Nordic and European research centre for regional development and planning [57]. The CI indicator demonstrates the impact that second homes have on the local rural communities [40,58]. The indicator is based on the relationship between the estimated annual population and the permanent population of rural municipalities [40,58]. CI can be calculated with the following equation, where PP stands for permanent population and $\mathrm{SH}$ for the number of second homes in the municipality.

$$
C I=\frac{P P+3 * S H}{P P}
$$

In equation 4 , the number of second homes is multiplied by three, which is an estimate of the average household size that utilizes these second homes [40]. The CI can be used as an indicator for the potential community impact recreational tourism made by second home owners has in the municipality [58]. If there are few second homes in a municipality, the number of annual inhabitants (AI) and regular population are nearly equal, and the CI indicator is close to one [58]. In contrast, a large CI indicator indicates a high level of second homes relative to inhabitants who live permanently in the municipality [40,58][40].

Ten municipalities with largest number of second homes from each Nordic country are used to calculate the combined rural CIs used in this study as the seasonal residency criterion. Calculation is done with statistics gathered by Nordregio [40]. The most popular second home municipalities are logical locations for proposed rural EV-sharing operations due to influx of yearly stable tourism made by seasonal residents.

In addition to seasonal residents, tourists are potential users of sharing services in rural areas. Tourists require short-term use of services such as shared EVs, which allow flexible and spontaneous movement in rural areas. On the other hand, moving in rural areas without a car is almost impossible as the distances are long and there exists no comprehensive network of public transportation. Tourists are also one of the main users of car rental services. In addition, the Nordic countries have a long tradition of domestic rural tourism and the potential for international rural tourism is growing [42]. As there exists no uniform rural tourism statistics from Nordic countries, tourist guest nights in 2019 per Nordic country were selected as the criterion that represents tourism in this study. Data for this criterion was gathered from the Nordic Statistics database [52].

Sharing services, and especially car sharing services, are relatively popular in Nordic countries. For instance, according to a Eurostat survey conducted in 2019, in Iceland, 23 percent of respondents had used a website or app to arrange a transport service from another individual [59]. The corresponding figure was 8 in Finland, Denmark, and Sweden [59]. Similarly, in Norway, 9 percent of respondents reported that they have used a website or app to arrange a transport service from another individual [59].

If people have previous experience of using shared services and shared cars, they are more willing to use these services in a new context or new locations, such as in rural areas. Therefore, the case countries were ranked based on people's previous experiences of using shared services. The basis for this ordinal criteria was the Eurostat survey concentrating on the use of collaborative economy services [59]. The Nordic countries were ranked based on the average survey results related to the use of websites or apps to arrange accommodation and transport services.

People living in large cities and especially in city centers are less likely to own cars than those who are living in rural areas and small towns [50]. This applies particularly to the capital regions [50]. Non-car owners are the most potential users of the shared cars, as they need vehicles especially for long weekends and holiday trips to the countryside [50]. For these reasons, the proportion of cars in relation to the population in Nordic metropolitan areas was chosen as a criterion. Metropolitan area vehicle fleet sizes and populations 
were gathered from official statistics of each Nordic country [60-69].

The final criterion is the potential of ancillary services providable by EVs in the rural region. For this criterion, the Nordic countries were ranked based on the participation possibilities EVs have on ancillary electricity service marketplaces. EVs connected to chargers can be used to balance the power grid via different demand response programs. Participation to these programs helps the grid stability and is encouraged with monetary incentives for participants. Participation to, for instance, frequency containment reserve (FCR) markets are however not open for power loads, such as EV charging, in all Nordic countries. The ordinal ranking for this criteria was done based on ENTSO-Es and Iceland's transmission system operator Landsnets' data $[70,71]$.

The selected criteria and their values for all Nordic countries presented in table 1 . Of the criteria, seasonal tourism (S_RES), tourism (TOURISM) and car ownership (VEHICLES) are cardinal, and experience with sharing economy services (S_ECON) and potential for ancillary services (ANC_SERV) ordinal criteria.

Table 1. Criteria considered in the analysis

\begin{tabular}{lrrrrr}
\hline Alternative & S_RES & \multicolumn{1}{c}{ TOURISM } & S_ECON & VEHICLES & ANC_SERV \\
\hline Finland & 1.48 & 18658358 & 4 & 0.53 & 1 \\
Sweden & 1.86 & 46427917 & 2 & 0.39 & 4 \\
Norway & 1.79 & 25024305 & 3 & 0.52 & 3 \\
Denmark & 1.68 & 21037168 & 5 & 0.55 & 2 \\
Iceland & 3.52 & 4533065 & 1 & 1.24 & 5 \\
\hline
\end{tabular}

\section{Results}

This section introduces the results of the stochastic multicriteria acceptability analysis performed with alternatives, criteria and criteria values of table 1 . The analysis was conducted without any known preference information for criteria weights.

The results of the rank acceptability analysis are presented in table 2 and figure 1 . In table 2 , the rank acceptability indices are the horizontal categories ( $\mathrm{r} 1$ stands for first rank etc.), and the values for alternatives represent the acceptability of an alternative for that rank. For instance, based on table 2, Sweden is the most accepted alternative for the first rank with $67 \%$ acceptability. Norway and Denmark however have an acceptability of $0 \%$ for the first rank, and thus they are the least preferred options based on this analysis.
Table 2. Rank acceptability indices for the alternatives

\begin{tabular}{|c|c|c|c|c|c|}
\hline Alternative & r1 & $\mathrm{r} 2$ & r3 & $\mathrm{r} 4$ & r5 \\
\hline Finland & 0,09 & 0,17 & 0,24 & 0,27 & 0,22 \\
\hline Sweden & 0,67 & 0,27 & 0,04 & 0,02 & 0,01 \\
\hline Norway & 0,00 & 0,38 & 0,44 & 0,15 & 0,04 \\
\hline Denmark & 0,00 & 0,03 & 0,23 & 0,53 & 0,21 \\
\hline Iceland & 0,24 & 0,14 & 0,06 & 0,04 & 0,53 \\
\hline
\end{tabular}
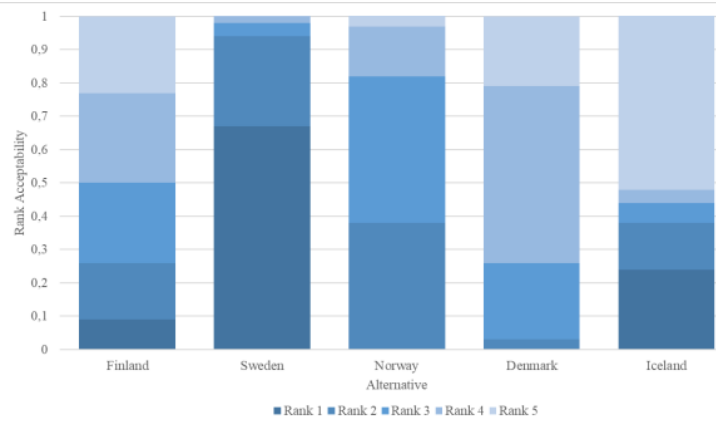

Figure 1. Rank acceptability

The rank acceptability indices for the alternatives are additionally depicted in figure 2 as a 3D bar graph. This graph illustrates the distribution of rank acceptabilities between the alternatives. It can be seen that Sweden performs well and has high acceptability values for first ranks and low values for ranks 3-5. The rank acceptabilities for other alternatives have more variance, for instance, Iceland has the second largest acceptability for the first rank, but it is also the most accepted alternative for the last rank, making it an unreliable choice.

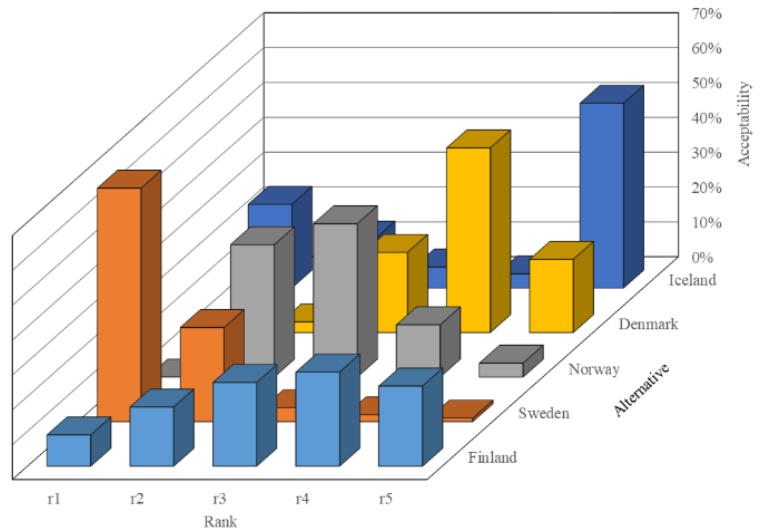

Figure 2. Rank acceptability indices of alternatives (\%)

The confidence factors and central weights for alternatives are presented in table 3 . The confidence factors represent the probability of an alternative to be the most preferred if the decision maker's preferences coincide with the presented central weights. The confidence factors of top 3 alternatives are $100 \%, 100 \%$ and $72 \%$ respectively. This means that Sweden and 
Iceland can be chosen with $100 \%$ confidence if the decision maker approves the central weights of corresponding alternatives.

Table 3. Central weights and confidence factor (CF) for alternatives and criteria

\begin{tabular}{|c|c|c|c|c|c|c|}
\hline Alternative & $\mathrm{CF}$ & S_RES & TOURISM & S_ECON & VEHICLES & $\overline{A N C \_S E R V}$ \\
\hline Finland & 0,72 & 0,11 & 0,09 & 0,14 & 0,17 & 0,50 \\
\hline Sweden & 1,00 & 0,15 & 0,25 & 0,19 & 0,24 & 0,17 \\
\hline Norway & 0,02 & 0,15 & 0,06 & 0,08 & 0,19 & 0,53 \\
\hline Denmark & 0,05 & 0,16 & 0,07 & 0,07 & 0,12 & 0,58 \\
\hline Iceland & 1,00 & 0,38 & 0,10 & 0,25 & 0,09 & 0,17 \\
\hline
\end{tabular}

The central weights of different alternatives are additionally plotted in figure 3 . Central weights reveal the preferences that are favorable for each alternative. For instance, it can be seen, that Denmark, Norway and Finland are favored by emphasizing ancillary services (ANC_SERV) somewhat more than other criteria. Iceland is the most preferred alternative with emphasis on seasonal residency (S_RES, 38\%), while vehicle ownership (VEHICLES) has only a little importance $(9 \%)$.

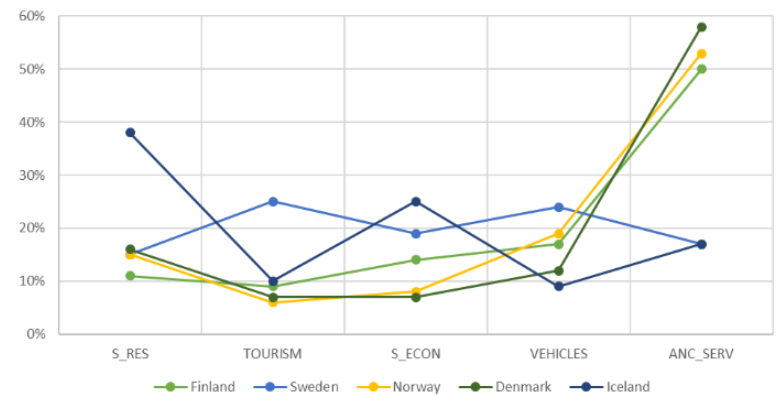

Figure 3. Central weights of alternatives

Overall, based on the rank acceptability indices, confidence factors and central weights, it seems that Sweden would be the logical first choice as the first pilot country. Sweden is the most accepted alternative for the first rank and the least preferred alternative for the last ranks based on rank acceptability analysis. Additionally, the central weights of Sweden have the least variance, and thus the decision maker does not have to put a significant emphasis on a certain criterion in order to justify this selection. Sweden also has a confidence factor of $100 \%$ with the central weights presented in table 3 , thus if the decision maker's preferences coincide with these weights, the probability of Sweden to be the most preferred alternative is $100 \%$. Overall, it can be stated that if the decision maker has no significant opinions that one criterion should have more importance in the decision than others, Sweden is a safe choice for the first rank.

\section{Discussion \& Implications}

According to the results of our SMAA-analysis, Sweden is the most promising country for a rural EV sharing pilot. Sweden was the most accepted alternative for the first rank based on conducted rank acceptability analysis with $67 \%$ acceptability for the first rank and had the lowest acceptabilities for last ranks. That is, based on rank acceptability alone, Sweden would be a safe choice for a rural EV-pilot.

However, based on central weight and confidence factor analysis, Iceland and Finland would also be viable alternatives for the pilot. Sweden and Iceland reached a confidence factor of $100 \%$ in this analysis, signifying that both these alternatives could be chosen with full confidence if the final decision makers would agree to preference weights presented in table 3 . However, Iceland could be chosen as the most suitable location only if the decision makers emphasizes the seasonal residency criterion more than other criteria. If all criteria were seen somewhat equally important, Sweden would be the most suitable alternative for the rural EV-pilot.

Sweden has the largest number of tourist guest nights and, the lowest vehicle ownership rate of metropolitan area compared to other Nordic countries. It seems that rural EV sharing ventures are supported especially by a large number of (rural) tourists and low vehicle ownership rate in the metropolitan area. In future region-scale analysis, data is needed from each prospective rural region. However as pointed out in [15], gathering this data from rural regions is difficult, and there exists no open data on for instance rural tourism from Nordic rural communities.

Our analysis also shows that people's previous experience with sharing economy services supports car sharing in rural areas. This is supported by previous studies such as [16]. In [16], the authors note that the success of shared car services is affected by how informed people are about sharing services and this is true especially in rural areas.

Seasonal residence also has an impact on the potential of shared car system in rural areas. However, the impact of this criteria is smaller than other criterion such as tourism, vehicle ownership rate and experience with sharing economy services. Ancillary services provided by shared EVs is the least critical criterion according to our analysis. Despite Sweden being the least favored by this criterion, it achieves the first overall rank in the performed acceptability analysis.

Based our results and the existing literature we suggest that a Swedish rural community relatively close to an urban city would be the ideal location for an EV sharing pilot. We propose that the pilot is a station based one-way EV sharing system, that is located close to a public transportation hub such as a bus or train station. 
This way the shared vehicles are accessible to tourists and second homeowners who come to the rural area by public transport. This kind of car sharing supports rural tourism and enables urban second homeowners to visit their second homes without a necessity to own a private vehicle. Additionally, establishing one-way EV sharing systems is less cost-intensive, and the one-way pilot can in the future be upgraded to a two-way system with stations in nearby urban areas, tourist attractions and other rural transportation hubs.

Uncertainty of our study is mainly related to the criteria selection and the data. The criteria used in our analysis is gathered mainly from previous studies concerning car sharing. However, as most of the previous studies focus on urban car sharing, some alterations had to be done for the rural case. Most uncertainty however arises from the country level data used in the analysis. For instance, tourist guest nights per country was used as a criterion, but it does not distinguish tourism in rural areas and urban areas. As pointed out earlier, region-scale data is however difficult to gather or non-existent. In the future the analysis should be extended to regional scale with data gathered straight from each addressed rural region either via interviews or prospective regional statistics.

\section{Conclusions}

Multiple criteria have to be considered when comparing viable locations for a rural EV sharing. Based on earlier research and locational aspects, Nordic rural regions affected by seasonal residence would be ideal locations for a rural EV sharing pilot. In this study, we utilized stochastic multicriteria acceptability analysis (SMAA) in this multicriteria decision problem.

The suitability of rural areas of Nordic countries for an EV-sharing pilot was analyzed based on five criteria. These criteria are seasonal residency, tourism, experience with sharing services, car ownership and potential of ancillary services providable by EVs in the region. Based on our analysis, Swedish rural regions experiencing seasonal counterurbanization would be the safest choice for an EV sharing pilot. Based on our analysis, the most important criteria for this kind of decision-making problem are tourism and vehicle ownership. Overall, high tourism and low vehicle ownership increases demand for shared mobility, and thus improves the profitability of shared EV systems.

The results of the conducted stochastic multicriteria acceptability analysis highlight the fact that with different preferences, different alternatives can be the most preferred choices. However, even with a major emphasis on the least critical criterion, ancillary services, the choice of Denmark or Norway for the pilot location could not be made with high confidence.
Whereas Iceland could be a confident choice if most emphasis is on seasonal residency, but on average this would be a poor choice as Iceland is the most accepted alternative for last rank in this comparison.

Overall, Sweden would be the confident choice for a rural EV sharing pilot, based on our novel application of SMAA to this multicriteria decision making problem. However, more research and region-scale data would be needed to verify these results and to extend the problem to regional level. Especially useful would be to interview potential decision makers in order to verify the suitability of the criteria used in this study, and in order to gather some tentative preference information that could be utilized in future analysis.

\section{References}

[1] Frenken, K. "Political Economies and Environmental Futures for the Sharing Economy." Philosophical Transactions of the Royal Society A: Mathematical, Physical and Engineering Sciences, Vol. 375, No. 2095, 2017, p. 20160367.

[2] Zervas, G., Proserpio, D., and Byers, J. W. "The Rise of the Sharing Economy: Estimating the Impact of Airbnb on the Hotel Industry." Journal of marketing research, Vol. 54, No. 5, 2017, pp. 687-705.

[3] Schor, J. "Debating the Sharing Economy." Journal of Self-Governance and Management Economics, Vol. 4, No. 3, 2016, pp. 7-22.

[4] Hamari, J., Sjöklint, M., and Ukkonen, A. "The Sharing Economy: Why People Participate in Collaborative Consumption." Journal of the association for information science and technology, Vol. 67, No. 9, 2016, pp. 2047-2059.

[5] Martin, C. J. "The Sharing Economy: A Pathway to Sustainability or a Nightmarish Form of Neoliberal Capitalism?" Ecological economics, Vol. 121, 2016, pp. 149-159.

[6] SMARTA. Report on Rural Good Practices. 2019.

[7] Shaheen, S. A., and Cohen, A. P. "Growth in Worldwide Carsharing: An International Comparison." Transportation Research Record, Vol. 1992, No. 1, 2007, pp. 81-89.

[8] Bellos, I., Ferguson, M., and Toktay, L. B. "The Car Sharing Economy: Interaction of Business Model Choice and Product Line Design." Manufacturing \& Service Operations Management, Vol. 19, No. 2, 2017, pp. 185-201.

[9] Martin, E. W., and Shaheen, S. A. "Greenhouse Gas Emission Impacts of Carsharing in North America." IEEE Transactions on intelligent transportation systems, Vol. 12, No. 4, 2011, pp. 1074-1086.

[10] He, L., Mak, H.-Y., Rong, Y., and Shen, Z.-J. M. "Service Region Design for Urban Electric Vehicle Sharing Systems." Manufacturing \& Service Operations Management, Vol. 19, No. 2, 2017, pp. 309-327.

[11] Wappelhorst, S., Sauer, M., Hinkeldein, D., Bocherding, A., and Glaß, T. "Potential of Electric Carsharing in Urban and Rural Areas." Transp. Res. Procedia, Vol. 4, No. January, 2014, pp. 374-386. 
[12] Crozier, C., Morstyn, T., and McCulloch, M. "The Opportunity for Smart Charging to Mitigate the Impact of Electric Vehicles on Transmission and Distribution Systems." Applied Energy, Vol. 268, 2020, p. 114973. https://doi.org/https://doi.org/10.1016/j.apenergy.2020. 114973.

[13] Yazdandoust, M., and Golkar, M. A. Participation of Aggregated Electric Vehicles in Demand Response Programs. In Electric Vehicles in Energy Systems, Springer, 2020, pp. 327-357.

[14] Nakayama, S., Yamamoto, T., and Kitamura, R. "Simulation Analysis for the Management of an Electric Vehicle-Sharing System: Case of the Kyoto Public-Car System." Transportation research record, Vol. 1791, No. 1, 2002, pp. 99-104.

[15] Illgen, S., and Höck, M. "Establishing Car Sharing Services in Rural Areas: A Simulation-Based Fleet Operations Analysis." Transportation, Vol. 47, No. 2, 2020, pp. 811-826.

[16] Rotaris, L., and Danielis, R. "The Role for Carsharing in Medium to Small-Sized Towns and in Less-Densely Populated Rural Areas." Transportation Research Part A: Policy and Practice, Vol. 115, 2018, pp. 49-62.

[17] Pelissari, R., Oliveira, M. C., Amor, S. Ben, Kandakoglu, A., and Helleno, A. L. "SMAA Methods and Their Applications: A Literature Review and Future Research Directions." Annals of Operations Research, 2019, pp. 1-61.

[18] Lahdelma, R., Hokkanen, J., and Salminen, P. "SMAAStochastic Multiobjective Acceptability Analysis." European Journal of Operational Research, Vol. 106, No. 1, 1998, pp. 137-143.

[19] Lahdelma, R., and Salminen, P. "SMAA-2: Stochastic Multicriteria Acceptability Analysis for Group Decision Making." Operations research, Vol. 49, No. 3, 2001, pp. 444-454.

[20] Lahdelma, R., Miettinen, K., and Salminen, P. "Ordinal Criteria in Stochastic Multicriteria Acceptability Analysis (SMAA)." European Journal of Operational Research, Vol. 147, No. 1, 2003, pp. 117-127.

[21] Lahdelma, R., Salminen, P., and Hokkanen, J. "Locating a Waste Treatment Facility by Using Stochastic Multicriteria Acceptability Analysis with Ordinal Criteria." European Journal of Operational Research, Vol. 142, No. 2, 2002, pp. 345-356.

[22] Cáceres, R. G. G., Durand, J. A. A., and Gómez, F. P. "Integral Analysis Method-IAM." European Journal of Operational Research, Vol. 192, No. 3, 2009, pp. 891903.

[23] Menou, A., Benallou, A., Lahdelma, R., and Salminen, P. "Decision Support for Centralizing Cargo at a Moroccan Airport Hub Using Stochastic Multicriteria Acceptability Analysis." European Journal of Operational Research, Vol. 204, No. 3, 2010, pp. 621629.

[24] Awasthi, A., Breuil, D., Chauhan, S. S., Parent, M., and Reveillere, T. "A Multicriteria Decision Making Approach for Carsharing Stations Selection." Journal of Decision Systems, Vol. 16, No. 1, 2007, pp. 57-78.

[25] Li, W., Li, Y., Fan, J., and Deng, H. "Siting of Carsharing Stations Based on Spatial Multi-Criteria Evaluation: A Case Study of Shanghai EVCARD." Sustainability, Vol. 9, No. 1, 2017, p. 152.

[26] MAMBA. Mobility for All in Rural Areas. 2020.

[27] Millard-Ball, A. Car-Sharing: Where and How It
Succeeds. Transportation Research Board, 2005.

Klintman, M. Between the Private and the Public: Formal Carsharing as Part of A Sustainable Traffic System. An Exploratory Study. 1998.

[29] Burghard, U., and Dütschke, E. "Who Wants Shared Mobility? Lessons from Early Adopters and Mainstream Drivers on Electric Carsharing in Germany." Transportation Research Part D: Transport and Environment, Vol. 71, 2019, pp. 96-109. https://doi.org/https://doi.org/10.1016/j.trd.2018.11.011

[30] Celsor, C., and Millard-Ball, A. "Where Does Carsharing Work? Using Geographic Information Systems to Assess Market Potential." Transportation Research Record, Vol. 1992, No. 1, 2007, pp. 61-69.

[31] Grossberg, R., and Newenhouse, S. Community Car: A New Transportaiton Option for Madison, Wisconsin.

[32] Eerola, A., and Jørgensen, B. H. Technology Foresight in the Nordic Countries. Ris $\emptyset$ National Laboratory, 2002.

[33] Skjelvik, J. M., Erlandsen, A. M., and Haavardsholm, O. Environmental Impacts and Potential of the Sharing Economy. Nordic Council of Ministers, 2017.

[34] Dølvik, J. E., and Jesnes, K. Nordic Labour Markets and the Sharing Economy:-Report from a Pilot Project. Nordic Council of Ministers, 2018.

[35] Kester, J., Noel, L., de Rubens, G. Z., and Sovacool, B. K. "Policy Mechanisms to Accelerate Electric Vehicle Adoption: A Qualitative Review from the Nordic Region." Renewable and Sustainable Energy Reviews, Vol. 94, 2018, pp. 719-731.

[36] Langhelle, A., Lossius, H. M., Silfvast, T., Björnsson, H. M., Lippert, F. K., Ersson, A., and Søreide, E. "International EMS Systems: The Nordic Countries." Resuscitation, Vol. 61, No. 1, 2004, pp. 9-21.

[37] Einarsdottir, J., Purola, A.-M., Johansson, E. M., Broström, S., and Emilson, A. "Democracy, Caring and Competence: Values Perspectives in ECEC Curricula in the Nordic Countries." International Journal of Early Years Education, Vol. 23, No. 1, 2015, pp. 97114.

[38] Beery, T. H. "Nordic in Nature: Friluftsliv and Environmental Connectedness." Environmental Education Research, Vol. 19, No. 1, 2013, pp. 94-117.

[39] Nicholls, S., and Amelung, B. "Implications of Climate Change for Rural Tourism in the Nordic Region." Scandinavian Journal of Hospitality and Tourism, Vol. 15, Nos. 1-2, 2015, pp. 48-72.

[40] Slätmo, E., Ormstrup Vestergård, L., Lidmo, J., and Turunen, E. Urban-Rural Flows from Seasonal Tourism and Second Homes: Planning Challenges and Strategies in the Nordics.

[41] Baldacchino, G., Helgadóttir, G., and Mykletun, R. J. Rural Tourism: Insights from the North Atlantic.

[42] Fredricsson, K., and Smas, L. Small-Scale Tourism in Rural Areas: Trends and Research in the Nordic Countries. Nordic Working Group 1B: Future Rural Areas. Working Paper 3/2013. Nordregio, Stockholm, 2013.

[43] Helgadóttir, G., and Dashper, K. "20 Years of Nordic Rural Tourism Research: A Review and Future Research Agenda." Scandinavian Journal of Hospitality and Tourism, 2020, pp. 1-10.

[44] Pouta, E., Sievänen, T., and Neuvonen, M. "Recreational Wild Berry Picking in Finland- 
Reflection of a Rural Lifestyle." Society and Natural Resources, Vol. 19, No. 4, 2006, pp. 285-304.

[45] Müller, D. K. "Second Homes in the Nordic Countries: Between Common Heritage and Exclusive

Commodity." Scandinavian Journal of Hospitality and Tourism, Vol. 7, No. 3, 2007, pp. 193-201.

[46] Åkerlund, U., Lipkina, O., and Hall, C. M. "Second Home Governance in the EU: In and out of Finland and Malta." Journal of Policy Research in Tourism, Leisure and Events, Vol. 7, No. 1, 2015, pp. 77-97.

[47] Kietäväinen, A. T., Rinne, J., Paloniemi, R., and Tuulentie, S. "Participation of Second Home Owners and Permanent Residents in Local Decision Making: The Case of a Rural Village in Finland." FenniaInternational Journal of Geography, Vol. 194, No. 2, 2016, pp. 152-167.

[48] Back, A., and Marjavaara, R. "Mapping an Invisible Population: The Uneven Geography of Second-Home Tourism." Tourism Geographies, Vol. 19, No. 4, 2017, pp. 595-611.

[49] Adamiak, C., Pitkänen, K., and Lehtonen, O. "Seasonal Residence and Counterurbanization: The Role of Second Homes in Population Redistribution in Finland.” GeoJournal, Vol. 82, No. 5, 2017, pp. 10351050 .

[50] Liikennevirasto. "Yhteiskäyttöautojen Potentiaali Ja Vaikutukset Käyttäjänäkökulmasta.” Liikenneviraston tutkimuksia ja selvityksiä, Vol. 25, 2018.

[51] Shaheen, S. A., Cohen, A. P., and Roberts, J. D. "Carsharing in North America: Market Growth, Current Developments, and Future Potential." Transportation Research Record, Vol. 1986, No. 1, 2006, pp. 116-124.

[52] Nordic Statistics. TOUR03: Guest Nights by Reporting Country, Nationality and Time.

https://pxweb.nordicstatistics.org/pxweb/en/Nordic Statistics/Nordic

Statistics_Business_Tourism/TOUR03.px. Accessed Jul. 12, 2020.

[53] Lahdelma, R., and Salminen, P. Stochastic Multicriteria Acceptability Analysis (SMAA). In Trends in multiple criteria decision analysis, Springer, 2010, pp. 285-315.

[54] Tervonen, T. "JSMAA: Open Source Software for SMAA Computations." International Journal of Systems Science, Vol. 45, No. 1, 2014, pp. 69-81.

[55] Awasthi, A., Chauhan, S. S., Hurteau, X., and Breuil, D. "An Analytical Hierarchical Process-Based Decision-Making Approach for Selecting Car-Sharing Stations in Medium Size Agglomerations." International Journal of Information and Decision Sciences, Vol. 1, No. 1, 2008, pp. 66-97.

[56] Deveci, M., Canıtez, F., and Gökaşar, I. "WASPAS and TOPSIS Based Interval Type-2 Fuzzy MCDM Method for a Selection of a Car Sharing Station." Sustainable Cities and Society, Vol. 41, 2018, pp. 777-791.

[57] Nordregio. About Nordregio. https://nordregio.org/about/. Accessed Sep. 30, 2020.

[58] Steineke, J. M. "The Impact of Recreational Homes." Journal of Nordregio, Vol. 3, No. 7, 2007, pp. 10-11.

[59] Eurostat. Individuals - Use of Collaborative Economy (until 2019).

[60] Tilastokeskus. 11ic -- Ajoneuvokanta Alueittain (Ml. Ahvenanmaa), 2011-2019. http://pxnet2.stat.fi/PXWeb/pxweb/fi/StatFin/StatFin lii_mkan/statfin_mkan_pxt_11ic.px/. Accessed Jul. $12,2020$.
[61] Tilastokeskus. Kuntien Avainluvut. https://www.stat.fi/tup/alue/kuntienavainluvut.html\#?ac tive1=MK01\&year=2020. Accessed Jul. 12, 2020.

[62] Transport Analysis. Vehicle Statistics. https://www.trafa.se/en/road-traffic/vehicle-statistics/. Accessed Jul. 8, 2020.

[63] Statistics Sweden. Population in the Country, Counties and Municipalities on December 31, 2019 and Population Change in October-December 2019. https://www.scb.se/en/finding-statistics/statistics-bysubject-area/population/populationcomposition/population-statistics/pong/tables-andgraphs/quarterly-population-statistics--municipalitiescounties-and-the-whole-country/quarter-4-2019/. Accessed Jul. 8, 2020.

[64] Statistics Norway. Registered Vehicles. https://www.ssb.no/en/statbank/table/07832/. Accessed Jul. 10, 2020.

[65] Statistics Norway. Population. https://www.ssb.no/en/statbank/table/01222/tableView Layout1/. Accessed Jul. 10, 2020.

[66] Statistics Denmark. BIL707: Stock of Vehicles per 1 January by Region and Type of Vehicle. https://www.statbank.dk/statbank5a/selectvarval/define. asp?PLanguage $=1 \&$ subword $=$ tabsel $\&$ MainTable $=$ BIL7 $07 \&$ PXSId $=111093 \&$ tablestyle $=\&$ ST $=$ SD \&buttons $=0$. Accessed Jul. 12, 2020.

[67] Statistics Denmark. BY2: Population 1. January by Municipality, Size of the City, Age and Sex. https://www.statbank.dk/statbank5a/SelectVarVal/Defi ne.asp? Maintable $=$ BY2\&PLanguage $=1$. Accessed Jul. 12, 2020.

[68] Statistics Iceland. Population by Locality, Age and Sex 1 January 2011-2019.

https://px.hagstofa.is/pxen/pxweb/en/Ibuar/Ibuar__man nfjoldi_2_byggdir__Byggdakjarnar/MAN03105.px. Accessed Jul. 5, 2020

[69] Statistics Iceland. Vehicles. https://www.statice.is/statistics/businesssectors/transport/vehicles/. Accessed Jul. 12, 2020.

[70] ENTSO-E. Survey on Ancillary Services Procurement, Balancing Market Design 2018. Brussels, 2019.

[71] Landsnet. Ancillary Services. https://www.landsnet.is/english/business/developmentprojects/ancillary-services. Accessed Jul. 12, 2020. 